\title{
Investment decisions under uncertainty on LNG-powered vessels for environmental compliance
}

\author{
Shun Chen, Shiyuan Zheng ${ }^{*}$ and Qiang Zhang
}

\author{
* Correspondence: syzheng@shmtu. \\ edu.cn \\ School of Transportation, Shanghai \\ Maritime University, 1550, Haigang \\ Ave, Pudong District, Shanghai, \\ China
}

\begin{abstract}
The shipping industry is investigating alternative fuels for ships, in order to comply with stricter emission requirements implemented by International Maritime Organization (IMO). Liquefied Natural Gas (LNG) is a promising alternative since it could reduce emissions substantially and offer potential fuel cost savings. But the investment in LNG fuelled vessels is currently facing a high degree of uncertainty, such as the differential between the prices of LNG and conventional maritime fuels, the availability of LNG and the reliability of its supply chain.

This paper makes an attempt to study the possibility of investing in LNG powered vessels under uncertainty. A deferral option model is proposed to quantify the value of flexibility for deferral based on multi-variables following specified stochastic processes. By exploiting the stochastic processes, it is possible to determine the value of deferral by solving a dynamic program using a least squares Monte Carlo simulation. The model is tested on an investment of a new chemical vessel with 19,000 dwt powered by LNG. Empirical analysis may suggest different investment strategies based on the probabilities of exercising an option and related option values each year. It indicates further that the attractiveness of $L N G$ as ship fuel is dominated by a couple of parameters: difference of ship prices between a LNG powered vessel and a reference one, the price differential between LNG and conventional fuel prices, the share of the sailing time inside Emission Control Areas (ECAs), and the supply cost of LNG.
\end{abstract}

Keywords: LNG powered vessel, Environmental compliance, Deferral option model, Monte Carlo simulation

\section{Introduction}

The shipping industry is a substantial emitter of air pollutants such as nitrogen oxides $\left(\mathrm{NO}_{\mathrm{x}}\right)$, sulphur oxides $\left(\mathrm{SO}_{\mathrm{x}}\right)$, carbon monoxide $(\mathrm{CO})$ and carbon dioxide $(\mathrm{CO} 2)$, because the vast majority (95\%) of the world's shipping fleet runs with engines powered by Intermediate Fuel Oil (IFO) for economic reasons (Cullinane and Bergqvist 2014). Though IFOs are cost effective, they contain high levels of asphalt, carbon residues, sulphur and metallic compounds and have high viscosity and low volatility properties as well.

The International Maritime Organization (IMO) is responsible for regulations on ship emissions aiming at protecting and improving the ocean environment. The Annex VI of the international convention for the Prevention of Pollution from Ships (MARPOL) came into force on 19 May 2005 and a Annex VI with tightened limits was 
adopted in October 2008 entering into force on 1 July 2010. In the Annex VI, limits are set on emissions of sulphur dioxide and nitrogen oxides both in Emission Control Areas (ECAs) and in global waters. The caps of ship gas emissions, in particular $\mathrm{SO}_{\mathrm{x}}$ and $\mathrm{NO}_{\mathrm{x}}$, are subject to a series of step changes over the years, which are described in Tables 1 and 2 .

In order to meet these emission requirements, there are diverse abatement technologies that could be adopted by ship owners. Table 3 shows a summary of the emission reduction systems currently used in ships (Burel et al. 2013). Among all of these measures, the most realistic alternatives are three if the focus is to reduce $\mathrm{SO}_{\mathrm{x}}$ and $\mathrm{NO}_{\mathrm{x}}$ emissions, suggested by Acciaro (2014). The first is the switch to higher-quality fuels, low in sulphur contents. The second is the use of exhaust gas cleaning systems, often referred to as maritime scrubbers, in combination with selective catalytic reduction to reduce nitrogen oxides for new vessels. And the third one is the use of vessels operating on LNG. Ship specifications, advantages and disadvantages of these three alternatives can be demonstrated in Table 4. It is further discussed in Acciaro (2014) that the use of scrubbers at sea is not well established due to the lack of detailed technical studies and accurate cost figures. Therefore, the alternative of installing exhaust gas cleaning systems is out of the scope and the focus is on distillate fuels (distillate oils include diesel fuels and fuel oils, e.g. Marine Gas Oil (MGO) and Intermediate Fuel Oil (IFO)) or on LNG.

Among the technologies that are currently evaluated, the possibility for ships of switching to LNG as a main fuel has gained significant concerns during the last few years. The use of LNG as the fuel for vessels has potentially substantial advantages, since LNG allows for a significant reduction of $\mathrm{NO}_{\mathrm{x}}, \mathrm{SO}_{\mathrm{x}}$. It is quite attractive in particular for ECA compliance, as clearly demonstrated in Table 3. However, technical maturity, availability and costs appear to be the most critical issues for the success of LNG as a maritime fuel on a large scale (Acciaro et al. 2013).

The investment returns of two alternatives of using distillate oils or LNG are greatly dependent on the price differences between distillate oils and LNG. However, the future prices of LNG are largely unknown as an international market for natural gas does not exist and the future prices of IFO and MGO are largely volatile caused by global unstable economic and political situations. The uncertainty associated with price differentials among fuels could not be taken into consideration in a traditional discounted cash flow (DCF) analysis when making the economic evaluation of the ship investment. The traditional approach assumes that management, having made the decision to initiate a capital investment, will manage cash flows continuously as planned until the end of its pre-specified useful life. This approach ignores the ability of management to adapt or revise decisions in response to unexpected market developments (Lai and Trigeorgis 1995; Bendall and Manger 1988; Bendall and Stent 2007).

Table 1 Fuel sulphur contents: global and ECA limits

\begin{tabular}{llll}
\hline Date & Global limit [\% mass] & Date & ECA limit [\% mass] \\
\hline Prior to 1/1 2010 & $4.5 \%$ & Prior to 1/7/2010 & $1.5 \%$ \\
After 1/1 2010 & $3.5 \%$ & After 1/7/2010 & $1.0 \%$ \\
After 1/1 2020 & $0.5 \%$ & After 1/1/2015 & $0.1 \%$ \\
\hline
\end{tabular}

Source: Burel et al. (2013) 
Table $2 \mathrm{NO}_{x}$ emission reduction programme

\begin{tabular}{lllll}
\hline Tier & Date & & & \\
\cline { 3 - 5 } & & $n<130$ & $130 \leq n \geq 2000$ & $n \geq 2000$ \\
\hline Tier I & 2000 & 17.0 & $45 \times n^{-0.2}$ & 9.8 \\
Tier II & 2011 & 14.4 & $44 \times n^{-0.23}$ & 7.7 \\
Tier III & $2016^{\mathrm{a}}$ & 3.4 & $9 \times \mathrm{n}^{-0.2}$ & 1.96 \\
\hline
\end{tabular}

$n=$ engine speed [rpm]

a only for $\mathrm{NO}_{\mathrm{x}}$ ECAs (TIER II applies outside ECAs)

Source: Burel et al. (2013)

Real Options Analysis (ROA), in contrast, incorporates both the uncertainty inherent in the operating business environment and the ability to actively manage, control or alter, (albeit to switch inputs or technology, expand, abandon, defer, etc.) a project in response to the changing circumstances when new information becomes available (Trigeorgis 1991, 1993a, 1993b; Bendall and Stent 2007). There is a wide body of literature in the field of real options. Trigeorgis $(1995,1996)$ amongst others provide a good summary of the field. Till now the Real Option Analysis (ROA) has been applied successfully into the shipping industry to analyze managerial strategies, see Alizadeh and Nomikos (2009) for a review, including the decision to enter or exit a certain market (Dixit 1989, 1992); the extension of a time charter agreement (Bjerksund and Ekern 1995); the investment in a new service (Bendall and Stent 2003); the switch between dry and wet markets (Sødal et al. 2008, 2009); the investment in new vessels or portfolio of vessels (Hopp and Tsolakis 2004; Bendall and Stent 2003, 2005, 2007; Dikos 2008); or the change of flag for a vessel (Kavussanons and Tsekrekos 2011).

Until recently, the real options used for investment related to environmental compliance in shipping can be seen in Acciaro et al. (2013) and Acciaro (2014), which proposes a decision support model for ship owners based on the use of an option to defer in order to assess the viability of postponing investment in retrofitting vessels for environmental compliance. One of the main limitations in Acciaro et al. (2013) is that the price differential between LNG prices and distillates was fixed. Although the limitation was overcome in Acciaro (2014) by making the price differential change yearly, prices of LNG and

Table 3 Gas emission reduction resulting from operating with different emission control systems compared to the use of LNG

\begin{tabular}{lllll}
\hline Abatement technology/measure & \multicolumn{3}{l}{ Emission reduction (\%) } \\
\cline { 2 - 4 } & $\mathrm{SO}_{x}$ & $\mathrm{NO}_{x}$ & $\mathrm{PM}$ & $\mathrm{CO}_{2}$ \\
\hline Basic internal engine modifications for 2 strokes, slow speed only & 0 & -20 & 0 & 0 \\
Advanced internal engine modifications & 0 & -30 & 0 & 0 \\
Direct water injection & 0 & -50 & 0 & 0 \\
Humid air motors & 0 & -70 & 0 & 0 \\
Exhaust gas recirculation + scrubbing & -93 & -35 & -63 & 0 \\
Selective catalytic reduction (2.7\% S residual oil fuel) & 0 & -90 & 0 & 0 \\
Sea water scrubbing & -75 & 0 & -25 & 0 \\
Fuel switching (from 2.7\% S to 1.5\% S IFO) & -44 & 0 & -18 & 0 \\
Fuel switching (from 2.7\% > 1.5\% S IFO) & -81 & 0 & -20 & 0 \\
Low S marine diesel (from 0.5\% to > 0.1\% S) & -80 & 0 & 0 & 0 \\
Liquefied Natural Gas (LNG) & -90 & -80 & -100 & -20 \\
\hline
\end{tabular}

Source: Burel et al. (2013) 
Table 4 Ship specifications, procs and cons of three emission abatement measures

\begin{tabular}{|c|c|c|c|}
\hline \multirow[t]{2}{*}{ Options } & A & B & C \\
\hline & $\begin{array}{l}\text { Oil powered } \\
\text { ship with SCR }\end{array}$ & $\begin{array}{l}\text { Oil powered ship } \\
\text { with scrubber + SCR }\end{array}$ & $\begin{array}{l}\text { LNG powered } \\
\text { ship with SCR }\end{array}$ \\
\hline \multicolumn{4}{|c|}{ Main engines and propulsion } \\
\hline Engine type & Diesel & Diesel & Dual Fuel Diesel \\
\hline Propulsion system & Direct & Direct & Direct \\
\hline \multicolumn{4}{|l|}{ Auxiliary engine } \\
\hline Engine type & Diesel & Diesel & Dual Fuel Gas \\
\hline Fuel (in ECA) & $\begin{array}{l}\text { LSFO (Low Sulphur } \\
\text { Fuel Oil) }(0.1 \% \text { S) }\end{array}$ & $\mathrm{IFO}$ & LNG, LSFO $(0.1 \% \mathrm{~S})$ \\
\hline Off ECA & LSFO (0.5\% S) & & LNG \\
\hline SCR & Installed & Installed & Installed \\
\hline Scrubber & Not & Installed & Not \\
\hline Procs & $\begin{array}{l}\text {-No or little } \\
\text { modifications and } \\
\text { investment needed } \\
\text {-Well known and } \\
\text { tested }\end{array}$ & $\begin{array}{l}\text {-Lower fuel costs } \\
\text {-Fuel available }\end{array}$ & $\begin{array}{l}\text {-Potential CO2 reduction } \\
\text {-Much lower maintenance }\end{array}$ \\
\hline Cons & $\begin{array}{l}\text {-Higher fuel costs } \\
\text {-Fuel availability uncertain } \\
\text {-Wear and tear }\end{array}$ & $\begin{array}{l}\text {-Higher OPEX, fuel } \\
\text { consumption and } \\
\text { maintenance costs } \\
\text {-Ship design and } \\
\text { stability challenges } \\
\text {-Sludge management: } \\
\text { need to create a logistics } \\
\text { chain and adapt port } \\
\text { infrastructure }\end{array}$ & $\begin{array}{l}\text {-More space needed for } \\
\text { the gas system on board } \\
\text {-Bunkering points and } \\
\text { associated logistics to be } \\
\text { created } \\
\text {-Safety aspects increase } \\
\text { complexity of the supply } \\
\text { chain, ship design } \\
\text { and operations } \\
\text {-Skilled and trained crew }\end{array}$ \\
\hline
\end{tabular}

${ }^{a}$ means the contribution of $\mathrm{LNG}$ as the fuel to $\mathrm{CO}_{2}$ reduction remains a topic of debate

distillates are just one sample of the fuel price distributions. If the sample path is changed, cost savings will be changed as well, and this may significantly influence the results.

In our paper, we propose a deferral option model where fuel prices are characterized by the mean-reverting geometric Brownian motion, and 300 sample paths are used to calculate the frequency of an investment opportunity. A dynamic program is designed to determine the value of the flexibility by making use of a least squares Monte Carlo simulation algorithm.

The main differences of our research with previous studies rest with three aspects. First, investment approaches incorporating uncertainty are abundant, but very little has dealt satisfactorily with non-stationary variables. In our study, fuel prices are characterized by non-stationary stochastic processes, because it seems not possible to make the prediction of these prices in the long term. Second, how the optimal time to invest changes with different paths and under different assumptions about market conditions is assessed. Third, various scenarios influencing the time to exercise option are discussed, providing support for shipping companies to make the investment decisions. The proposed model not only provides a tool to analyze the investment strategy under uncertainty, but it also provides an insight into the interdependency of variants influencing the investment in LNG powered vessels and will show the required flexibility in the decision-making for shipping companies.

This paper is structured as follows. The next section describes a proposed analytical modelling approach to measure the value of flexibility in deferring under non-stationary stochastic demand using real options solution methodologies. This is followed by a 
presentation of the data properties. We then proceed to present the empirical analysis. Some conclusions and directions for further research are addressed in the last section.

\section{Methodology}

Uncertainty in real option analysis can be modelled as nonstationary stochastic processes, where the distribution may change over time. According to Dixit and Pindyck (1994), a stochastic process is defined as 'a variable that evolves over time in a way that is at least in part random.'

Two common forms of such processes are the Geometric Brownian Motion with drift and the Ornstein-Uhlenbeck mean-reverting process. In relation to the LNG and distillate fuels markets, Geometric Brownian Motion (GBM) model, however, seems to have some drawbacks due to the fact that it does not capture the special characteristics such as mean reversion. Given a starting price, GBM would accept this as a normal event and would proceed randomly from there with no consideration of prior price levels and no greater probability of returning to the average price level. It allows that the price fluctuation could reach an unrealistic level when GBM is used to model spot prices. Mean reversion can be thought of a modification of the random walk, where price changes are not completely independent of one another but rather are related. Hence, prices of distillate fuels and LNG are supposed to follow mean-reverting processes in our study, which is bolstered by Li (2007), who argues that over time, the process of fuel prices tends to drift towards its long-term mean: such a process is called mean-reverting.

The geometric Brownian motion of Intermediate Fuel Oil (IFO) and LNG prices with mean-reverting can be defined by Dixit and Pindyck as:

$$
\begin{aligned}
& d P_{o, t}=\eta_{o}\left(\bar{P}_{o}-P_{o, t}\right) P_{o, t} d t+\sigma_{o} P_{o, t} d W \\
& d P_{g, t}=\eta_{g}\left(\bar{P}_{g}-P_{g, t}\right) P_{g, t} d t+\sigma_{g} P_{g, t} d W
\end{aligned}
$$

Where $P_{o, t}$ means IFO prices at time t. $\bar{P}_{o}$ is the mean of the variable $P_{o, t}, P_{g, t}$ refers to LNG prices at time t, $d W$ is an increment in a Wiener process and $\eta_{g}$ and $\sigma_{g}$ are parameters, $\bar{P}_{g}$ denotes the mean of the variable $P_{g, t} \cdot \eta_{o}$ and $\sigma_{o}$ are parameters.

Trigeorgis (1996) presents a framework for using real options in strategic management by expanding on the NPV:

$$
\text { Expanded NPV }=\mathrm{NPV}+\text { option premium }
$$

The NPV is expanded on by incorporating the option premium, which represents the value from options that a static NPV analysis would not be able to capture. Benaroch and Kauffman (2000) present a clear comparison of this valuation versus a traditional discounted cash flow method. Chow and Regan (2011) conclude that many different kinds of real options can fit into the option premium in the framework provided by Trigeorgis. For example, Benaroch (2002) lists the many types of real options that can apply to information technology, including deferral, staging, scaling, abandonment, outsourcing, leasing, and compounding (interaction of multiple options).

Given an expiration time $\mathrm{T}$ and a project value based on one or more nonstationary stochastic processes, the problem of deciding the optimal time to exercise an option can 
be interpreted as an optimal stopping problem, according to Dixit and Pindyck (1994). An example of a real option defined as a stopping problem is the deferral option.

The deferral option can be solved via dynamic programming and it involves optimizing the binary decision to continue a process for another incremental time period or to stop it at the current time period. The problem is decomposed into a backward dynamic program, where the objective function in each time state is defined as follows:

$$
\Phi_{t}\left(x_{t}\right)=\max _{u_{t}}\left\{\pi_{t}\left(x_{t}, u_{t}\right)+e^{-\rho \Delta t} E_{t}\left[\Phi_{t+\Delta t}\left(x_{t+\Delta t}\right)\right]\right\}
$$

Where $u_{t}$ is the decision to continue or stop the process at time $t, \pi_{t}$ is the profit flow in the current time state as a function of $u_{t}$ and state variable $x_{t}, \rho$ is the discount rate for continuous compounding, $E_{t}$ is the expectation at time $t$, and $\Phi_{t}$ is the value of the control problem. Equation (3) is commonly called the Bellman equation or the fundamental equation of optimality (Dixit and Pindyck 1994).

In our research, the objective is to maximize the savings by comparing the operation of the LNG-powered vessel to a conventional one. The NPV of cost savings is based on the difference of total costs between these two types of vessels, as described in Eq. (4). According to Eq. (3), the proposed model in our paper actually is a Bellman equation for determining the value of an investment opportunity with an option to defer as a function of stochastic fuel prices, as can be seen in Eq. (5).

$$
\pi\left(P_{o}, P_{g}\right)=\sum_{j=1}^{n} \frac{1}{(1+\rho)^{j}} f\left(P_{o, j}, Q_{o, j}\right)-\sum_{j=1}^{n} \frac{1}{(1+\rho)^{j}} f\left(P_{g, j}, Q_{g, j}\right)+\Delta K_{o, g}+\frac{1}{(1+\rho)^{n}} \Delta R_{o, g}
$$

Where $\pi$ is the net present value of the total cost savings between a LNG fuelled vessel and a conventional one. $f\left(P_{o, j}, Q_{o, j}\right)$ denotes annual operational costs and voyage costs dependent on the stochastic fuel oil prices at time t. $f\left(P_{g, j}, Q_{g, j}\right)$ refers to annual operational costs and voyage costs dependent on the stochastic LNG prices at time t, $\Delta R_{o, g}$ means the difference of the residual values for two types, while $\Delta K_{o, g}$ is the difference of capital costs of two types of vessels.

$$
\Phi_{t_{n}}\left(P_{o, t_{n}}, P_{g, t_{n}}\right)=\max \left\{\pi_{t_{n}}\left(P_{o, t_{n}}, P_{g, t_{n}}\right),(1+\rho)^{-\Delta t} E\left[\Phi_{t_{n+1}}\left(P_{o, t_{n+1}}, P_{g, t_{n+1}}\right)\right]\right\}
$$

Where $\pi_{t_{n}}$ is the net present value of the total cost savings between a LNG fuelled vessel and a conventional one and it is a function dependent on the stochastic LNG prices, denoted as $P_{g, t_{n+1}}$ and fuel oil prices, denoted as $P_{o, t_{n+1}} . t_{n}$ is a time state such that $t_{n+1}-t_{n}=\Delta t$ and $n=T / \Delta t$ is the final time horizon, but $n=0$ is the initial time state being solved for.

In this example, the process is deferral and in each time state the problem is whether to continue deferring or to stop deferring and to invest immediately with a value of 0 . The problem can be solved using differential equations if the state variable is an Ito process.

The deferral option in the investment of LNG vessels is a single option dynamic programming problem with an objective function that depends on the stochastic LNG and fuel oil prices. Because of the complex nature of this problem, it is not suitable to use finite difference methods to solve them, which may have a high computational cost. In this case, a relatively fast converging numerical option valuation method is necessary. This requirement rules out traditional Monte Carlo simulation methods as well. The Least 
Squares Monte Carlo simulation method (LSM) refined by Longstaff and Schwartz (2001) is therefore chosen for solving the option value, see Chow and Regan (2011). To apply this method, fuel oil prices $P_{o, t}$ and LNG prices $P_{g, t}$ need to be in a discrete format and the certain assumptions need to be made for the cost function to obtain the PV.

The price simulation can be derived from Eqs. (1)-(2) if Ito's lemma is applied to these stochastic functions.

$$
\begin{aligned}
& P_{o, t}=P_{o, t-\Delta t} \exp \left(\left(\eta_{o}\left(\bar{P}_{o}-P_{o, t}\right)-\frac{1}{2} \sigma_{o}^{2}\right) \Delta t+\sigma_{o} W_{\Delta t}\right) \\
& P_{g, t}=P_{g, t-\Delta t} \exp \left(\left(\eta_{g}\left(\bar{P}_{g}-P_{g, t}\right)-\frac{1}{2} \sigma_{g}{ }^{2}\right) \Delta t+\sigma_{g} W_{\Delta t}\right)
\end{aligned}
$$

Where $\eta_{o}$ is a generalized drift parameter and $\sigma_{o}$ is a generalized diffusion parameter for oil-based prices; $\eta_{g}$ is a generalized drift parameter and $\sigma_{g}$ is a generalized diffusion parameter for LNG prices, and $W_{\Delta t}$ can be simulated with a normal inverse function with $\varepsilon \sqrt{\Delta t}$, where $\varepsilon \sim N(0,1)$ Time series data of fuel prices would be necessary to estimate the parameters.

\section{The LSM solution algorithm}

Because fuel prices are assumed to follow stochastic processes, numerical methods are necessary to solve realistic real option dynamic programming problems. Trigeorgis (1996) describes several common numerical methods developed to handle real option analysis. The methods can generally be categorized into three classes: finite difference, binomial lattice methods, or Monte Carlo simulation.

Chow and Regan (2011) point out that the finite difference method (Brennan and Schwartz 1977) is not very suitable for multiple options where the differential would be difficult to specify. The binomial lattice method (Cox et al. 1979) is not able to handle multidimensional variables very well because of its inherent method of simplifying probability distributions into branches. Traditional Monte Carlo simulation methods developed by Boyle (1977) are suitable in solving dynamic programming problems of multiple variables, while it has very high computational cost because at any time step, the backward dynamic program requires foreseeing the expected continuation function in the future time step. This complication resulted in the Least Squares Monte Carlo simulation method (LSM) refined by Longstaff and Schwartz (2001). LSM reduces the computational cost by using least squares regression at each intermediate step, based on the results of the following future time step along all the simulation paths (Chow and Regan 2011).

The LSM algorithm developed by Chow and Regan (2011) is applied into this research. The algorithm is shown below for given prices $P_{g, t_{n}}$ and $P_{o, t_{n}}$ with estimated parameters for Ito processes, interest rate $\rho$, time horizon $T$ and a number of simulation paths $P$.

1. For each path $\omega \in P$ and time state $t_{n}, 0 \leq n \leq T / \Delta t$, generate simulated LNG and fuel oil prices using Eqs. (6)-(7).

2. For the known $P_{t_{0}}$ and for each of the simulated $P_{t_{n}}(\omega), 0 \leq n \leq T / \Delta t, \omega \in P$, evaluate an objective such as Eq.(4) to obtain $\pi_{t_{n}}$ or the cost function valuation algorithm to obtain $\pi_{t_{n}}\left(P_{g, t_{n}}, P_{o, t_{n}}\right)$.

3. Starting from $n=T / \Delta t$, use LSM to solve the backward dynamic program Eq. (5). 
(1) If $n=T / \Delta t$, let $\Phi_{t_{n}}\left(P_{g, t_{n}}(\omega), P_{o, t_{n}}(\omega)\right)=\max \left(0, \pi_{t_{n}}\left(P_{g, t_{n}}, P_{o, t_{n}}\right)\right)$.

(2) Keep track of the optimal decision with the variable $\theta\left(\omega, t_{n}\right)$; if $\Phi_{t_{n}}\left(P_{g, t_{n}}(\omega), P_{o, t_{n}}\right.$ $(\omega))>0$, then that sample path is "in the money" and is assigned a value of $\theta(\omega$,

$\left.t_{n}\right)=1$. Otherwise, let $\theta\left(\omega, t_{n}\right)=0$.

(3) Let $n=n-1$. If $n=0$, go to step 4 .

(4) Estimate $\hat{\Phi}_{t_{n+1}}$ using least squares regression with Hermite polynomial series, although other polynomials that form an orthonormal basis such as Laguerre series can also be used:

$$
H_{i}(x)=(-1)^{i} e^{x^{2} / 2} \frac{d^{i}}{d x^{i}} e^{-x^{2} / 2}
$$

The $(i+1)$ th polynomial can be represented recursively as

$$
H_{i+1}(x)=x H_{i}(x)-i H_{i-1}(x)
$$

A regression function with $\Pi$ polynomials could be of the form

$$
\Phi_{t_{n+1}}=\sum_{i=0}^{\Pi} \beta_{i}(-1)^{i} e^{x^{2} / 2} \frac{d^{i}}{d x^{i}} e^{-x^{2} / 2}
$$

Where the $\beta_{i}$ coefficients are estimated using least squares. The $x$ values are $\left.\pi_{t_{n}}\left(P_{g, t_{n}}(\omega), P_{o, t_{n}}(\omega)\right)\right|_{\pi_{t_{n}>0}}$ at each simulation path at the particular time interval.

(5) Use the estimate $\hat{\Phi}_{t_{n+1}}$ to solve Eq. (5). If the optimal decision is to wait because $(1+\rho)^{-\Delta t} \cdot E\left[\hat{\Phi}_{t_{n+1}}\right]>\pi_{t_{n}}\left(P_{g, t_{n}}(\omega), P_{o, t_{n}}(\omega)\right)$, then the option on that simulation path is still in the money and $\theta\left(\omega, t_{n}\right)=1$.

(6) If $n>0$, go to step (3). Otherwise, the value obtained from Eq. (5) is the value of option.

4. If $\Phi_{t_{0}}>0$, then the option is worth keeping. If $\left.(1+\rho)^{-\Delta t} E\left[\hat{\Phi}_{t_{1}}\right]>\pi_{t_{0}}\left(P_{g, t_{0}}, P_{o, t_{0}}\right)\right)$ $>0$, then the best strategy is to defer the option. If $\Phi_{t_{0}}>0$ and $(1+\rho)^{-\Delta t} E\left[\hat{\Phi}_{t_{1}}\right] \leq$ $\left.\pi_{t_{0}}\left(P_{g, t_{0}}, P_{o, t_{0}}\right)\right)$ then the best strategy is to invest immediately.

5. The algorithm may need to be returned at increasing values of $\Pi$ until the option value stops increasing beyond some tolerance.

\section{Empirical analysis}

The real options analysis with LSM solution algorithm is applied to the investment strategy in shipping. As introduced in the first section, the most realistic alternatives are three if the focus is to reduce $\mathrm{SO}_{\mathrm{x}}$ and $\mathrm{NO}_{\mathrm{x}}$ emissions: the switch to higher-quality fuels, the use of exhaust gas cleaning systems, in combination with selective catalytic reduction to reduce nitrogen oxides for new vessels; and the use of vessels operating on LNG. Our research focuses on distillate fuels or LNG for a new chemical ship for the environmental compliance. The alternative of installing exhaust gas emission reduction devices, such as scrubbers, is beyond the scope of this paper, as explained in Section 1. Before presenting the model results, figures and information used in this paper will be explained at first. 


\section{Data description}

The model has been tested using a chemical vessel of 19,000 dwt burning LNG and a reference one burning maritime fuels. The specifications of the vessels are given in Table 5 below. In the analysis we assume the economic life of one vessel is 20 years. Ships are operated at the voyage of Houston-Ulsan. Days at sea are 340. The newbuilding price of the LNG powered ship in June 2015 was $\$ 34.4$ million and the price of a reference one is assumed to be $20 \%$ lower. Operational costs for the LNG powered ship are about $\$ 6000$ per day and that for a reference one are $\$ 5000$ daily. We assume the residual values of both ships are $25 \%$ of new ship values based on the previous data. Ship related data in this research are obtained from Stolt Nielsen Limited in Shanghai and Dingheng Shipbuilding Co. Ltd. The risk free interest rate is 3.5\% annually.

The study makes an attempt to solve the probability of each option of investing in a LNG powered vessel between 2016 and 2020. Costs are estimated of a LNG powered vessel in comparison to a reference vessel burning maritime fuel oils. For a conventional ship, $0.1 \%$ LSFO (low sulphur fuel oil) is used inside an ECA. Off the ECA, fuel oils not exceeding 3.5\% sulphur could be used by 2020, after which the global sulphur cap will be reduced to $0.5 \%$. For the LNG powered ship, dual-fuel low speed diesel engine is installed as main engine. LNG is the main fuel and LSFO is the pilot fuel, so SCR is required to comply with Tier III. At the voyage of Houston-Ulsan, it is estimated that one ship operates roughly $25 \%$ within the ECA annually.

In order to estimate annual voyage costs of both a LNG powered ship and a conventional one during their economical life, we simulate fuel prices, i.e. IFO, MGO and LNG, instead of using the fixed prices because of their stochastic properties. Weekly prices of IFO and MGO at Singapore are utilized over the period starting from Jan 1990 to June

Table 5 Ship Parameters for two types of chemical ships

\begin{tabular}{|c|c|c|c|}
\hline \multirow[t]{2}{*}{ Options } & \multirow[t]{2}{*}{ Unit } & \multirow{2}{*}{$\begin{array}{l}\text { Traditional Type } \\
\text { Oil ship with SCR }\end{array}$} & \multirow{2}{*}{$\begin{array}{l}\text { New Type }{ }^{b} \\
\text { LNG fuelled } \\
\text { ship with SCR }\end{array}$} \\
\hline & & & \\
\hline \multicolumn{4}{|l|}{ Main engines and propulsion } \\
\hline Engine speed & - & Low & Low \\
\hline Engine type & - & Diesel & Dual Fuel Diesel \\
\hline Propulsion system & - & Direct & Direct \\
\hline \multicolumn{4}{|l|}{ Auxiliary engine } \\
\hline Engine speed & - & Medium & Medium \\
\hline Engine type & - & Diesel & Dual Fuel gas \\
\hline Fuel (in ECA) & - & LSFO $(0.1 \% \mathrm{~S})$ & LNG, LSFO \\
\hline Off ECA & - & MGO $(0.5 \% \mathrm{~S})$ & LNG \\
\hline SCR & & Installed & Installed \\
\hline Deadweight & DWT & 19,000 & 19,000 \\
\hline Speed & Knot & 13.3 & 13.3 \\
\hline Days at sea & Days & 35 & 35 \\
\hline Days at ports & Days & 13 & 13 \\
\hline Fuel consumption at sea & Tonnes/day & 23.7 & 20.88 \\
\hline Fuel consumption at port(MGO) & Tonnes/day & 9.4 & 3.12 \\
\hline
\end{tabular}

Source: Stolt Nielsen Chemical Company in Shanghai and Dingheng Shipbuilding Co. Itd ${ }^{a}$ means the ship burning oil-based fuels, while ${ }^{b}$ denotes the ship burning LNG 
2015, resulting in 1325 observations. While weekly prices of LNG are from Jan 2000 to June 2015 due to the difficulty in the availability of the data and there are 804 observations. Since LNG prices at different bunkering stations vary substantially, LNG prices at Henry Hub in the USA and Japan are considered in this research for the voyage of Houston-Ulsan. The LNG prices at Japan and Henry Hub are market prices and LNG prices for the vessels actually include 10\% addition of the market prices as consumption tax and cost for LNG bunkering, as explained by Adachi et al. (2014). In other words, the supply cost of the LNG price is set initially at $10 \%$ of the market price. Prices of oil-based fuels are obtained from Clarksons Research Co. Ltd, n.d. and prices of LNG are from an Energy Consultancy Company in Beijing. The price patterns of all fuel prices could be seen in Figs. 1 and 2.

\section{Investment deferral option}

Uncertainty of an investment in a LNG powered ship lies in prices of oil-based fuels and LNG, each of which could evolve as a mean-reverting geometric Brownian motion, as explained in Section 1. The deferral option model can be solved in several steps as follows.

\section{Step 1: To simulate fuel prices and estimate the net present values of total costs}

Here, we use the method proposed by Dixit and Pindyck (1994) to estimate the parameters of IFO and LNG prices in Eqs. (6), (7). Because LNG prices at both Henry Hub in the USA and Japan are considered in this research, $\eta_{o}, \eta_{g h h}, \eta_{g j p}, \bar{P}_{o}, P_{g h h}^{-}, P_{g j p}^{-}, \sigma_{o}, \sigma_{g h h}$ and $\sigma_{g j p}$ are required to be estimated. First, the sample data are used to estimate the parameters $a_{o}, b_{o}, a_{g h h}, a_{g j p}, b_{g h h}$ and $b_{g j p}$ in the following equations by OLS:

$$
\begin{aligned}
& P_{o}^{t}-P_{o}^{t-1}=a_{o}+b_{o} P_{o}^{t-1}+\varepsilon_{o}^{t} \\
& P_{g h h}^{t}-P_{g h h}^{t-1}=a_{g h h}+b_{g h h} P_{g h h}^{t-1}+\varepsilon_{g h h}^{t} \\
& P_{g j p}^{t}-P_{g j p}^{t-1}=a_{g j p}+b_{g j p} P_{g j p}^{t-1}+\varepsilon_{g j p}^{t}
\end{aligned}
$$

Next, we can obtain the corresponding parameters as follows:

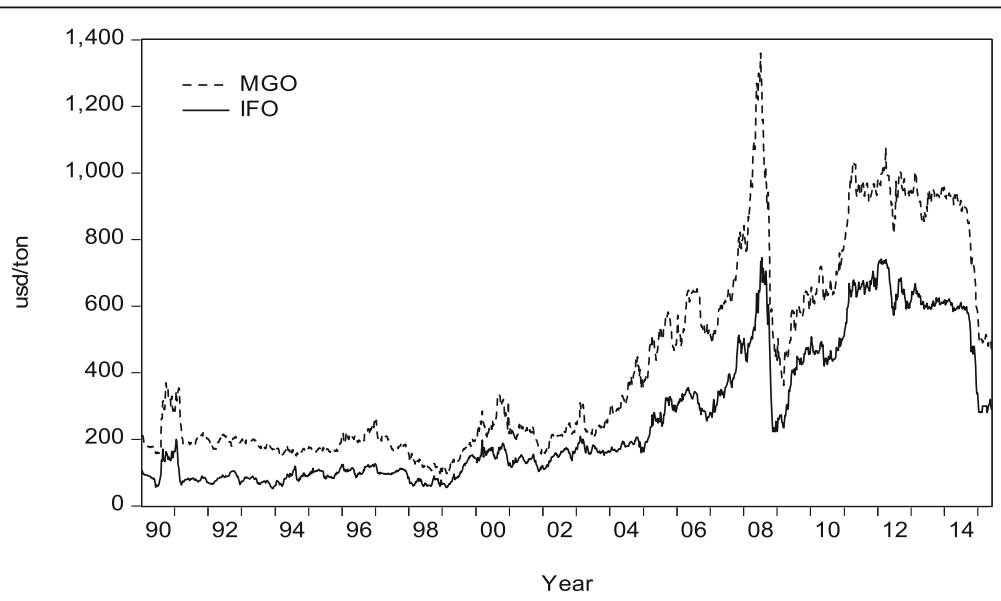

Fig. 1 Weekly IFO and MGO prices over the period of Jan 1990 to June 2015. Source: authors' own elaboration based on data from Clarksons Research Co. Ltd 


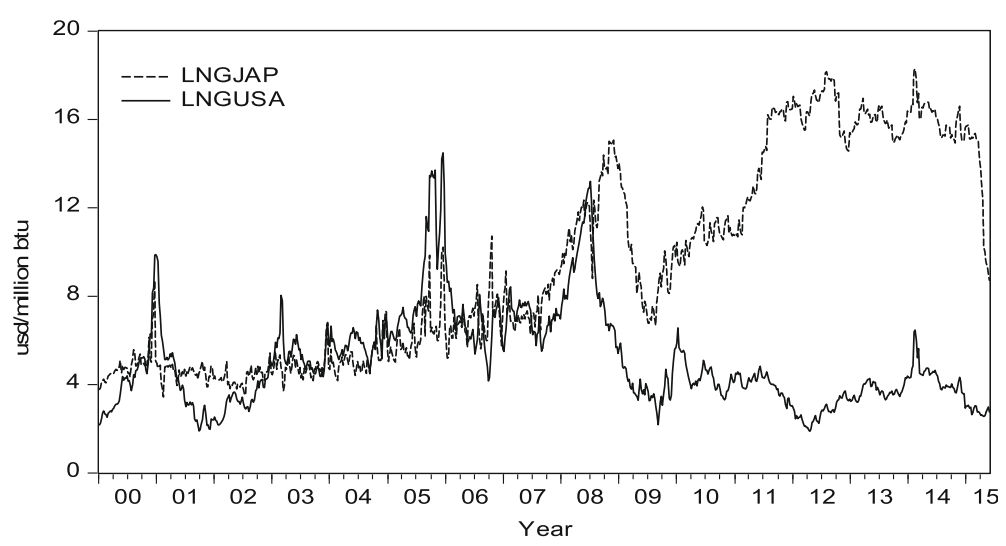

Fig. 2 Weekly LNG prices at Japan and Henry Hub over the period of Jan 2000 to June 2015. Source: authors' own elaboration based on data from an Energy Consultancy Company in Beijing

$$
\begin{aligned}
& \bar{P}_{o}=a_{o} / b_{o} \\
& \eta_{o}=-\log \left(1+b_{o}\right) \\
& \sigma_{o}=\sigma_{\varepsilon, o} \sqrt{\frac{\log \left(1+b_{o}\right)}{\left(1+b_{o}\right)^{2}-1}} \\
& P_{g h h}^{-}=a_{g h h} / b_{g h h} \\
& \eta_{g h h}=-\log \left(1+b_{g h h}\right) \\
& \sigma_{g h h}=\sigma_{\varepsilon, g h h} \sqrt{\frac{\log \left(1+b_{g h h}\right)}{\left(1+b_{g h h}\right)^{2}-1}} \\
& \sigma_{g j p}=\sigma_{\varepsilon, g j p} \sqrt{\frac{\log \left(1+b_{g j p}\right)}{\left(1+b_{g j p}\right)^{2}-1}} \\
& \eta_{g j p}^{-}=-\log \left(1+b_{g j p}\right) \\
& P_{g j p} / b_{g j p}
\end{aligned}
$$

Where $\sigma_{\varepsilon, o}, \sigma_{\varepsilon, g h h}$ and $\sigma_{\varepsilon, g j p}$ are the standard deviations of regression equations, respectively. $P_{g h h}$ refers to LNG prices at Henry Hub, $\bar{P}_{g h h}$ denotes the mean of the variable $P_{g h h} . P_{g j p}$ refers to LNG prices at Japan, $\bar{P}_{g j p}$ denotes the mean of the variable $P_{g g p}$. 
It's obvious that prices of IFO and MGO are closely related, because they are both products from crude oil. The price fluctuations are modelled as perfectly correlated based on the long-run average between both variables. (the long-run average could be derived from the cointegration relationships between IFO and MGO and the process could be obtained from Authors)

$$
\log P_{m g o, t}=\alpha \log P_{o, t}+\beta
$$

Where $P_{m g o, t}$ refers to MGO price, $P_{o, t}$ means IFO price at time $\mathrm{t}, \alpha$ is the parameter and $\beta$ the intercept.

For IFO prices, the data set used in our study consists of weekly IFO prices in Singapore covering the period from Jan 12th, 1990 to June 26th, 2015, yielding a sample of 1325 observations. For MGO prices, the data set comprises 1325 observations as well. For LNG prices at Henry Hub, the data set consists of weekly data from Jan 7th, 2000 to June 26th, 2015, producing a sample of 804 observations, and the same sample is applicable for LNG prices at Japan as well. Based on these sample data, we use Eviews 6.0 to obtain the estimated values of $a_{o}, b_{o}, a_{g h h}, a_{g j p}, b_{g h h}$ and $b_{g j p}$ and calculate parameters of regression equations. Results are presented in Table 6.

Once parameters are known, they can be used to simulate weekly price patterns during the next 25 years i.e. July 2015 to July 2040. In every pricing run, 300 paths are simulated for IFO, LNG prices at Henry Hub and LNG prices at Japan, and each of 300 paths is assumed to be equally likely. For each type of maritime fuels, we can acquire a matrix with observations of $1330 \times 300$. Based on the long-run relationship between IFO and MGO, the price patterns of MGO can be obtained as well. Figure 3 demonstrates one sample of price patterns for three maritime fuels.

Once we get simulated prices of maritime fuels over the period of June 2015 to June 2040, annual voyage costs could be estimated. The LNG costs of the LNG powered vessel are estimated based firstly on LNG prices at Henry Hub. The impacts of LNG prices at Japan on the changes of the total costs and the final investment decision will be discussed in the sensitivity analysis. Since daily operational costs and newbuilding prices are known for two types of chemical vessels, the net present value of total costs of running 20 years for both types can be estimated based on Eq. (4). Specifically, the investment option will be exercised within the period of 2016 to 2020, so for the first year (2016), the net present values of total costs over the next 20 years, i.e. 2016 to 2036 for 300 sample paths could be estimated. For the last year of this period (2020), NPVs of total costs over the next 20 years, i.e. 2020 to 2040 for 300 sample paths could

Table 6 Parameters of variables in Eqs. (6)-(7) and (23)

\begin{tabular}{lllllll}
\hline & Parameters & Estimates & Parameters & Estimates & Parameters & Estimates \\
\hline IFO & $\eta_{0}$ & 0.002456 & $\bar{P}_{o}$ & 5.5638 & $\sigma_{0}$ & 0.0377 \\
MGO & $a$ & 0.894557 & $\beta$ & 1.1109 & - & - \\
LNG henry hub & $\eta_{g h h}$ & 0.01616 & $\bar{P}_{g h h}$ & 1.5653 & $\sigma_{g h h}$ & 0.04939 \\
LNG $_{\text {japan }}$ & $\eta_{g j p}$ & 0.01376 & $\bar{P}_{g j p}$ & 2.1945 & $\sigma_{g j p}$ & 0.05562 \\
\hline
\end{tabular}

$\eta_{o}$ is a generalized drift parameter and $\sigma_{o}$ is a generalized diffusion parameter. $\bar{P}_{o}$ is the mean value of oil-based fuel prices. $\alpha$ is the parameter and $\beta$ the intercept in the cointegrating vector of the cointegration relationships between IFO and MGO. $\eta_{g h h}$ is a generalized drift parameter and $\sigma_{g h h}$ is a generalized diffusion parameter. $\bar{P}_{g h h}$ denotes the mean value of LNG prices at Henry Hub. $\eta_{g j p}$ is a generalized drift parameter and $\sigma_{g j p}$ is a generalized diffusion parameter. $\bar{P}_{g j p}$ denotes the mean value of LNG prices at Japan and $W_{\Delta t}$ can be simulated with a normal inverse function with $\varepsilon \sqrt{\Delta t}$ where $\varepsilon \sim N(0,1)$ 


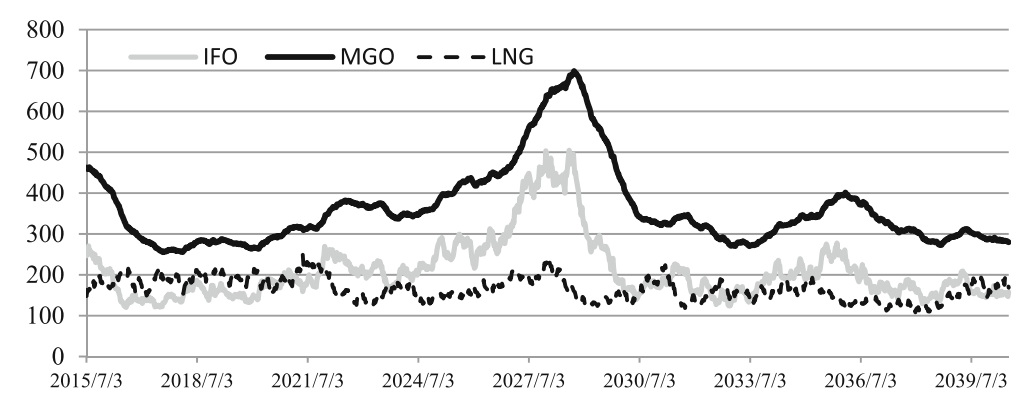

Fig. 3 One sample of simulated prices for maritime fuels over July 3rd 2015 to July 6th 2040

be estimated. Finally, we get a matrix of discounted costs with observations of $6 \times 300$ for each type of vessels. Once the discounted total costs are known, we can make a comparison of costs between a LNG powered vessel and a reference one. The net present values of total costs for both types of vessels in the case of ECA 25\% are demonstrated in Table 7.

\section{Step 2: to determine the optimal stopping time by using LSM program}

In order to use the LSM algorithm, the option needs to be exercised in discrete times in the interval $[0, T]$. In this research, the time to maturity is 2020 , the investment option could be exercised within the period of 2016 to 2020, so intervals (n) are 6 and the length $(\Delta t)$ is equal to 1 . The underlying variables $\left(P_{g, t_{n}}\right.$ and $\left.P_{o, t_{n}}\right)$ are then simulated with 300 paths.

Table 7 The net present values of total costs each period for 300 sample paths for two types of vessels (unit:\$)

\begin{tabular}{clllll}
\hline Sample path $j$ & $1-20^{\mathrm{a}}$ & $2-21$ & $3-22$ & $4-23$ & $5-24$ \\
1 & $93,652,148$ & $94,619,235$ & $96,308,355$ & $97,813,552$ & $99,229,020$ \\
2 & $87,457,616$ & $86,617,530$ & $85,429,349$ & $84,239,065$ & $83,983,471$ \\
3 & $91,875,435$ & $92,990,715$ & $94,714,786$ & $96,839,855$ & $99,295,831$ \\
& $114,598,621$ & $116,251,992$ & $117,713,689$ & $118,678,309$ & $119,689,962$ \\
298 & $93,650,277$ & $93,710,972$ & $93,995,208$ & $94,113,740$ & $94,653,258$ \\
299 & $93,532,797$ & $94,041,005$ & $94,933,723$ & $95,451,127$ & $95,576,234$ \\
300 & $82,098,887$ & $82,644,984$ & $83,956,705$ & $85,022,315$ & $85,737,473$
\end{tabular}

Part 2: The net present values of total costs each period for 300 sample paths for a LNG powered vessel

$\begin{array}{llllll}1 & 79,517,962 & 80,917,733 & 81,922,366 & 82,876,357 & 84,012,918 \\ 2 & 80,967,571 & 82,311,144 & 83,878,890 & 85,459,745 & 86,618,243 \\ 3 & 81,442,731 & 82,768,563 & 83,555,735 & 84,776,658 & 86,053,819 \\ 298 & 83,744,186 & 84,999,982 & 86,230,016 & 87,056,316 & 87,897,931 \\ 299 & 84,168,935 & 85,602,135 & 86,892,395 & 88,276,463 & 89,917,868 \\ 300 & 79,497,737 & 80,667,512 & 82,373,912 & 84,099,198 & 85,495,554 \\ & 79,918,498 & 81,261,929 & 82,257,027 & 83,598,094 & 84,725,689\end{array}$

${ }^{a} 1-20$ means the investment in 2016 and the ship will be operated for the next 20 years. 2-21 means the investment in 2017 and the ship will be operated for the next 20 years. 3-22 means the investment in 2018 and the ship will be operated for the next 20 years. 4-23 means the investment in 2019 and the ship will be operated for the next 20 years. 5-24 means the investment in 2020 and the ship will be operated for the next 20 years 
The optimal stopping time can be obtained using the Bellman Eq. (5) as explained in Section of Methodology.

$$
\Phi_{t_{n}}\left(P_{g, t_{n}}, P_{o, t_{n}}\right)=\max \left\{\pi_{t_{n}}\left(P_{g, t_{n}}, P_{o, t_{n}}\right),(1+\rho)^{-\Delta t} E\left[\Phi_{t_{n+1}}\left(P_{g, t_{n+1}}, P_{o, t_{n+1}}\right)\right]\right\}
$$

Where $\pi_{t_{n}}$ is the net present value of the total cost savings between a LNG fuelled vessel and a conventional one and it is a function dependent on the stochastic LNG prices, denoted as $P_{g, t_{n+1}}$ and fuel oil prices, denoted as $P_{o, t_{n+1}} \cdot t_{n}$ is a time state such that $t_{n+1}-t_{n}=\Delta t=1$ and $n=T / \Delta t=6$ is the final time horizon, but $n=0$ is the initial time state being solved for.

Since LSM will be used to solve the backward dynamic program, let's start with Year 5 , i.e. the year of 2020. In Year 5, the shipowner has the possibility of investing in a new technology or deferring the investment decision. Because $\Phi_{t_{n}}\left(P_{g, t_{n}}(\omega), P_{o, t_{n}}(\omega)\right)$ $=\max \left(0, \pi_{t_{n}}\left(P_{g, t_{n}}, P_{o, t_{n}}\right)\right)$, Keep track of the optimal decision with the variable $\theta\left(\omega, t_{5}\right)$; if $\Phi_{t_{5}}\left(P_{g, t_{5}}(\omega), P_{o, t_{5}}(\omega)\right)>0$ (it means the present value of total costs over 20 years of a ship burning oil-based fuels is larger than that of a LNG powered one), then that sample path is "in the money" and is assigned a value of $\theta\left(\omega, t_{5}\right)=1$. Otherwise, $\theta\left(\omega, t_{5}\right)=0$. We continue to go to Year 4 and do the same work till Year 1.

For all of paths with a value of 1, we estimate the expected values of all costs between two types of vessels following the approach explained in Part 2.1, and make the comparison between the present value of the expected value and the actual one. For example, in Year 4, if actual savings are larger than the present value of the expected ones, then that sample path is "in the money" and is assigned a value of 1 , otherwise, the value is 0 . We go back to Year 3. If actual savings in Year 3 are larger than the expected ones, Year 4 is replaced by Year 3, which is assigned a value of 1 . It is guaranteed that there is at most a value of 1 for one sample path during Year 1 to Year 5. Specifically, if there are all zeros over 5 years, it means the option is worth keeping and no investment will be performed. If there is a value of 1 in Year 1 and zeros for others, it means the best strategy is to invest immediately. Simulated results are demonstrated in Table 8.

The LSM simulation with 300 sample paths results in a distribution of options exercised shown in Table 9. This result indicates that in the case of ECA $25 \%, 77.7 \%$ of the time for the optimal decision to exercise the 5-year investment option would lie within the first year

Table 8 Simulation results of 300 sample paths in the case of ECA 25\% ${ }^{\mathrm{a}}$

\begin{tabular}{lllll}
\hline Sample path j & The optimal year to exercise & Option value $(\$)$ & Discount rate & Present value of savings (\$) \\
\hline 1 & 1 & $18,889,317$ & 1 & $18,889,317$ \\
2 & 2 & $8,481,576$ & 1.26248 & $6,718,203$ \\
3 & 0 & 0 & 0 & 0 \\
4 & 2 & $7,095,164$ & 1.26248 & $5,620,021$ \\
5 & 0 & 0 & 0 & 0 \\
298 & 1 & $15,268,176$ & 1 & $15,268,176$ \\
299 & 1 & $20,818,910$ & 1 & $20,818,910$ \\
300 & 0 & 0 & 0 & 0 \\
\multicolumn{2}{l}{ Simulated option value: } & & & $10,066,289$ \\
\hline
\end{tabular}

${ }^{\mathrm{a} E C A} 25 \%$ means a ship operates $25 \%$ inside ECAs annually 
Table 9 Sample distribution of time to exercise option for each year in the case of ECA 25\%

\begin{tabular}{llllllll}
\hline Year & 2016 & 2017 & 2018 & 2019 & 2020 & No exercise & Option Value \\
\hline Frequency & 233 & 9 & 1 & 1 & 2 & 54 & $\$ 100,266,289$ \\
Percent & $77.7 \%$ & $3 \%$ & $0.3 \%$ & $0.3 \%$ & $0.7 \%$ & $18 \%$ & \\
\hline
\end{tabular}

of realization. However, there is $18 \%$ of the time of choosing no investment within 5 -year period. The option value of all options exercised during 5 years reaches over $\$ 10$ million.

\section{Step 3: to consider some scenarios}

First, we assess the abatement option with focus on the operation time in the emission control areas (ECAs). Figure 4 shows the probability of exercising an option for vessels which operate $25 \%$ of one year within ECA waters and the second for vessels which operate $50 \%$, and the third for vessels operating $100 \%$ in the ECAs. The main observations from Fig. 4 suggest that an increase in the time spent in an ECA would increase the attractiveness of investing in a new LNG powered ship, and an immediate investment decision would be more preferable for all cases. In particular, when a ship operates the whole year inside an ECA, the probability of no investment is reduced to below $10 \%$ and that of exercising option at the first year is clearly increased to $90 \%$. If studying further all of these options exercised, we find that on average LNG needs a rebate of $\$ 100-\$ 150$ per ton to be competitive, bolstered by the findings in Lindstad et al. (2015).

Figure 5 compares the probability of exercising an option and the call option values for different new-built ship values. It should be noted that in our research it is the benchmark level for the ship value of a LNG powered ship 20\% higher than a conventional one. Suppose a vessel operates $25 \%$ of one year in an ECA. In this case, when a ship burning LNG is $30 \%$ more valuable than that of a reference one, $67 \%$ of the time for the optimal decision to exercise an investment option would lie within the first year, decreased from $77.7 \%$ when the price differential remains at $20 \%$. While when the price differential is narrowed to be $10 \%$, the probability of exercising the investment option

\begin{tabular}{|c|c|c|c|c|c|c|}
\hline \multicolumn{7}{|c|}{ \% } \\
\hline \multirow{2}{*}{\multicolumn{7}{|c|}{$\begin{array}{l}1.000 \\
0.900\end{array}$}} \\
\hline \multirow{2}{*}{\multicolumn{7}{|c|}{0.800}} \\
\hline \multirow{2}{*}{\multicolumn{7}{|c|}{0.700}} \\
\hline \multirow{2}{*}{\multicolumn{7}{|c|}{0.600}} \\
\hline \multirow{2}{*}{\multicolumn{7}{|c|}{0.500}} \\
\hline \multirow{2}{*}{\multicolumn{7}{|c|}{0.400}} \\
\hline \multirow{2}{*}{\multicolumn{7}{|c|}{0.300}} \\
\hline \multirow{2}{*}{\multicolumn{7}{|c|}{0.200}} \\
\hline \multirow{2}{*}{\multicolumn{6}{|c|}{0.100}} & \\
\hline \multirow{2}{*}{\multicolumn{7}{|c|}{0.000}} \\
\hline & & & & & & \\
\hline & 2016 & 2017 & 2018 & 2019 & 2020 & no exercise \\
\hline & & $5 \%$ & $\& \mathrm{EC}$ & & ECA & \\
\hline $\begin{array}{l}\text { Fig. } 4 \text { Pr } \\
\text { amount } \\
\text { ECA is } 50\end{array}$ & ies of & $\begin{array}{l}\text { goptio } \\
\text { an EC } \\
\text { plies th }\end{array}$ & $\begin{array}{l}\text { ous oper } \\
\text { of one y } \\
\text { operate }\end{array}$ & $\begin{array}{l}\text { me with } \\
\text { A50\% th } \\
\text { hole ye }\end{array}$ & $\begin{array}{l}\text { Notes: } \\
\text { nt of tim } \\
\text { ECA }\end{array}$ & $\begin{array}{l}25 \% \text { means the } \\
\text { sent sailing in an }\end{array}$ \\
\hline
\end{tabular}




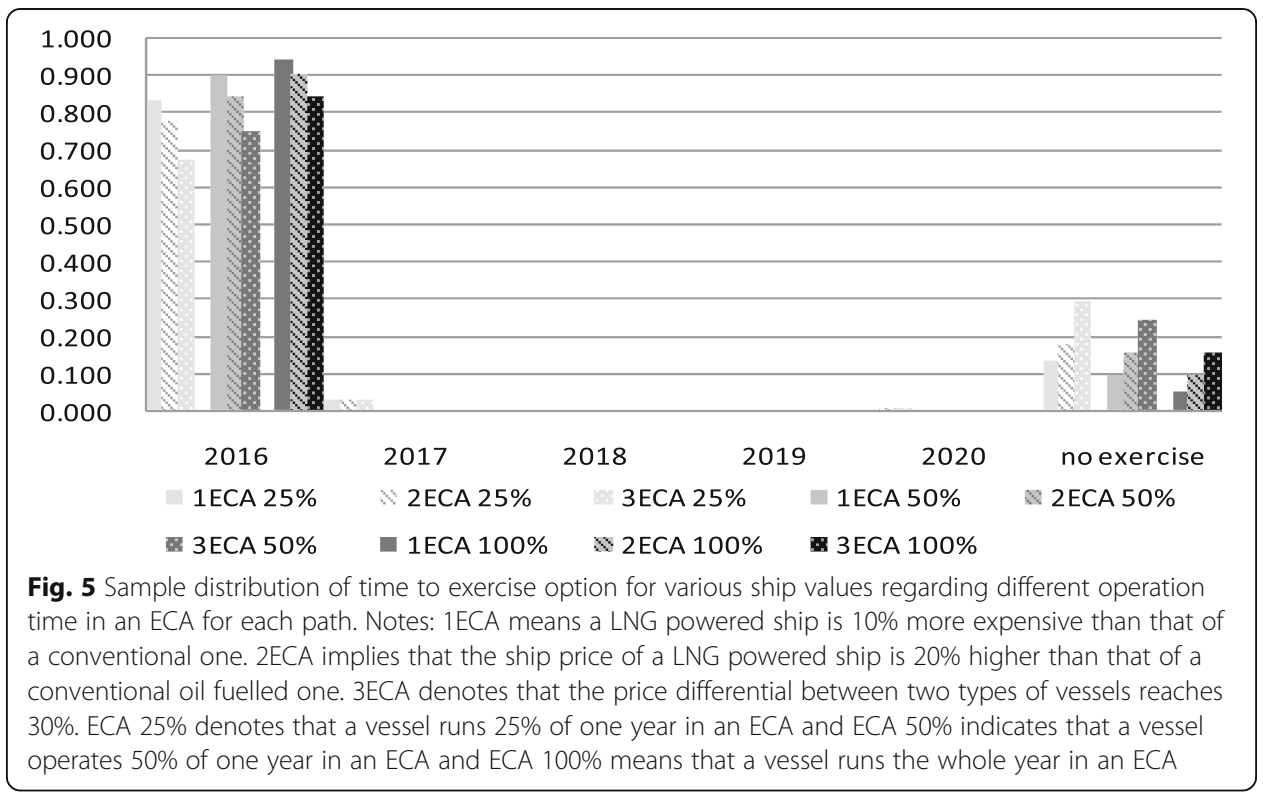

is significantly increased to be $83 \%$ and that of deferring the decision to the future or no investment over the 5 -year period is declined to be $13.7 \%$.

The similar findings can also be detected in the other two cases of ECA 50\%, i.e. a vessel operates $50 \%$ of 1 year in an ECA and ECA100\%, i.e. a vessel operates the whole year in an ECA. It is clearly seen that if a vessel spends more time sailing in an ECA and the ship is cheaper, this option would be more attractive. The results suggest that an immediate investment is more attractive and deferring the investment tends to be less valuable in general compared to the first case. It is interesting to find that if a vessel using LNG spends the whole year sailing in an ECA and the ship value is only $10 \%$ higher than that of a reference one, the result prefers an immediate investment in 2016, and the probability of no investment during a 5-year period is shrunk to $5.3 \%$.

It may be claimed that the model suggests an investment option in LNG depending on three parameters: the price differentials between LNG and oil-based fuels, the difference of new-building prices between a new ship burning LNG and a conventional one burning traditional maritime fuels, and the share of operation within ECAs.

Regarding the supply cost of LNG prices, we compare the impact of supply cost's changes on the investment decisions. It is noted that the supply cost of LNG prices is set initially at $10 \%$ of the market price in our case at the voyage of Ulsan-US Gulf. Figure 6 shows how the distribution of time to exercise option changes when the supply cost changes. It is observed that when the supply cost is increased to be $30 \%$ from an initial $10 \%$, the probability of an immediate investment will be reduced by $10.7,9$ and $9 \%$ if it operates 25,50 and $100 \%$ of 1 year in an ECA, respectively. The deferral decision can be used to reduce some of the variability or technological uncertainties related to the supply cost of bunkering LNG.

As far as LNG prices at different bunkering stations are concerned, we investigate the impact of different LNG prices on the investment decisions. When the LNG powered ship bunkers LNG at Japan instead of Henry Hub, the costs will be changed significantly. The simulation is again made by using LNG prices at Japan, and results in Fig. 7 demonstrate a significantly different distribution of time. 


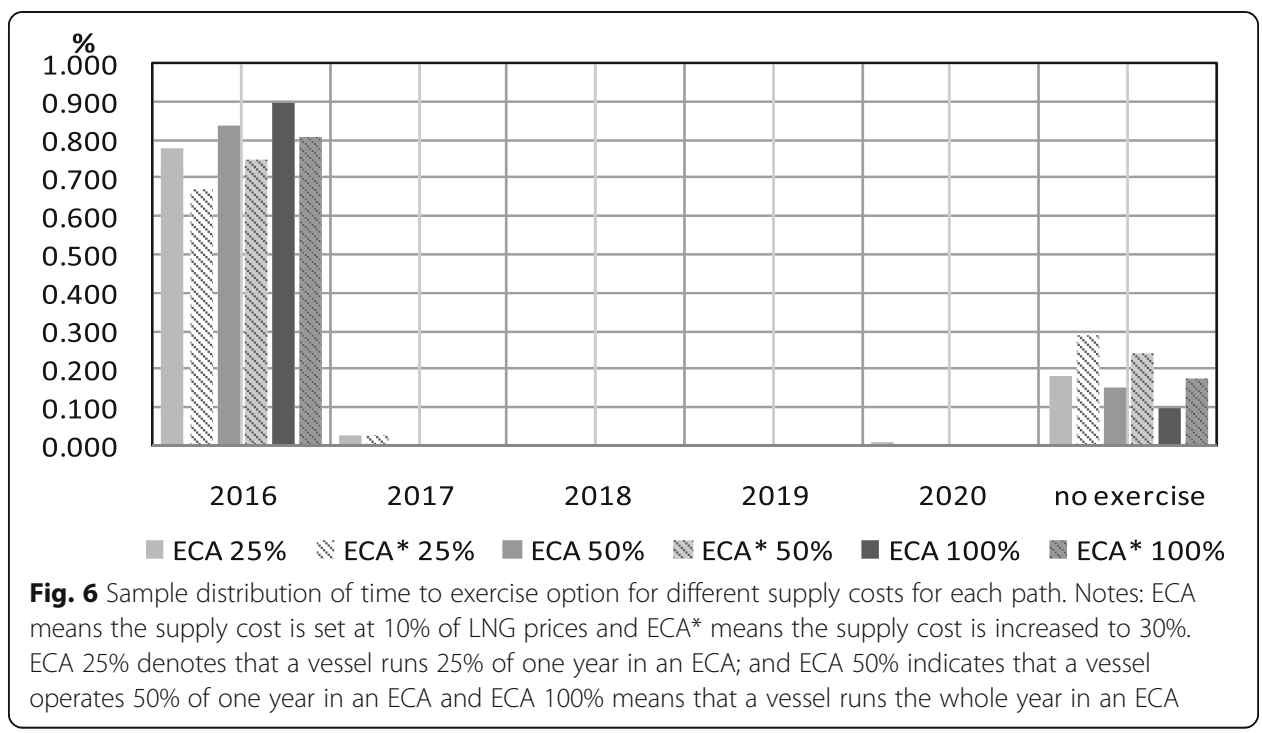

For the cases of ECA 25 and ECA 50\%, the results prefer waiting and no investment within the 5 -year period. For the case of ECA $100 \%$, only $12.3 \%$ of the time to exercise option would lie within the first year, and the result still suggests deferring the investment to the future after 2020 at the probability of $68.7 \%$.

In general, deferring the investment appears to be more valuable as a strategy if LNG prices at Japan are used in the model. This could be explained by higher mean values and bigger standardised deviation of the simulated LNG prices at Japan. In other words, LNG prices at Japan are significantly higher than those from Henry Hub in the USA. The bigger variability and mean values of LNG prices affect substantially the total savings obtainable between the operation of two types of vessels.

The results indicate that there is no single answer to what is the best optimal time of making an investment in a LNG fuelled ship. The best timing would be dependent on

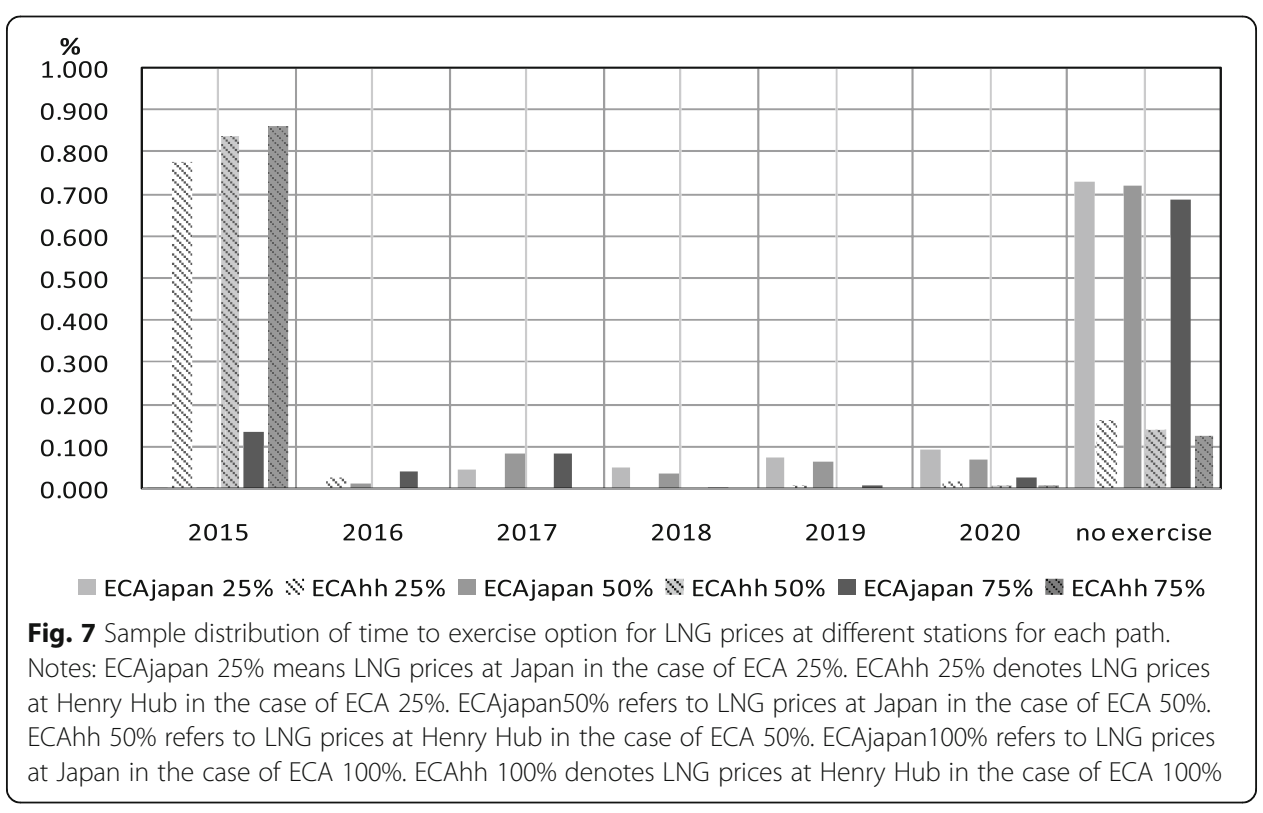


the amount of time spent sailing in ECAs, the price differential of ship values between two types of vessels, the supply cost related to the consumption tax and bunkering cost, and LNG prices at different stations.

\section{Conclusions}

The investment in LNG fuelled vessels is currently facing a high degree of uncertainty, such as the differential between the prices of LNG and conventional maritime fuels, the availability of LNG and the reliability of its supply chain. The discounted cash flow techniques cannot incorporate the flexibility to respond to new information and to defer the investment, therefore, real options analysis is favoured by academia to accommodate flexibility in the investment decision so that the valuation of a project can reflect operating and strategic adaptability.

The real options literature describes methods for quantifying the value of flexibility to execute such a strategy. Until recently, Chow and Regan (2011) have proposed an option methodology for network designs that feature multidimensional and stochastic variables. To date it has been the first time such an option methodology has been considered in deferring an investment in a LNG powered new ship related to environmental compliance in shipping. The proposed deferring option model is a numerical option evaluation method using the LSM algorithm to solve a backward dynamic program.

The prices of maritime fuels are assumed to follow the mean-reverting geometric Brownian motion, which are contained in the deferral option model. The model is solved following LSM algorithm proposed by Chow and Regan (2011). Based on the mean-reverting geometric Brownian motion equations, 300 sample paths of simulated weekly fuel prices over the period of 2015 to 2040 can be generated. Once fuel prices are given, the savings of the total costs for two types of chemical vessels can be computed. The deferral option model proposed in this paper can be solved by simulation within Matlab and the distribution of time to exercise option and the call option values are obtained for each path.

Results indicate that the attractiveness of LNG as the ship fuel compared to the use of distillate fuels is dominated by several parameters, including the price difference between LNG and IFO; the share of operation inside ECAs, the differential of new ship values between a LNG powered ship and a reference one and the supply cost.

The model to predict costs for LNG systems on board chemical vessels offers extensive possibilities to study additional variants. Options include different vessel sizes, fuel consumption of vessels, route profiles, and other LNG related operational costs.

In our study, we only examine the possibility of investing in a LNG powered vessel to comply with emission requirements of $\mathrm{SO}_{\mathrm{x}}$ and $\mathrm{NO}_{\mathrm{x}}$. While the contribution of $\mathrm{LNG}$ as the ship fuel to $\mathrm{CO}_{2}$ reduction sparks off considerable debate and it will be left for further study.

Acknowledgements

We thank the editor and anonymous referees for their valuable comments and suggestions. We are also grateful for comments from participants at the 14th World Conference on Transport Research in Shanghai, China, July 2016.

Funding

This paper is funded by Shanghai Natural Science Foundation (13ZR1418600). 
and testing it within Matlab. The third co-author QZ is responsible for the literature review concerning the abatement technologies of meeting emission requirements, and policies aiming to improve the ocean environment. All authors read and approved the final manuscript.

\section{Competing interests}

The authors declare that they have no competing interests.

\section{Publisher's Note}

Springer Nature remains neutral with regard to jurisdictional claims in published maps and institutional affiliations.

Received: 1 November 2017 Accepted: 18 April 2018

Published online: 25 April 2018

\section{References}

Acciaro M (2014) Real option analysis for environmental compliance: LNG and emission control areas. J Transp Res Part D 28(1):41-50

Acciaro M, Hoffmann PN, Eide MS (2013) The energy efficiency gap in maritime transport. J Ship Ocean Eng 3(10):1-10 Adachi M, Kosaka H, Fukuda T, Ohashi S, Harumi K (2014) Economic analysis of trans-ocean LNG-fuelled container ship. J Mar Sci Technol 19:470-478

Alizadeh AH, Nomikos NK (2009) Shipping derivatives and risk management. Palgrave MacMillan, Basingstoke Benaroch M (2002) Managing information technology investment risk: a real options perspective. J Manag Inf Syst 19(2):43-65 Benaroch M, Kauffman RJ (2000) Justifying electronic banking network expansion using real option analysis. MIS Q 24(2): $197-225$

Bendall H, Stent AF (2003) Investment strategies in market uncertainty. Marit Policy Manag 30(4):293-303 Bendall H, Stent AF (2007) Maritime investment strategies with a portfolio of real options. J Marit Policy Manage 34(5):441-452 Bendall HB, Manger G (1988) Corporate governance, capital structure and budgeting: preliminary evidence from the maritime industry. Inaugural Australasian Finance and Banking Conference, Australian Graduate School of Management, Sydney December

Bendall HB, Stent AF (2005) Ship investment under uncertainty: valuing a real option on the maximum of several strategies. J Marit Econ Logist 7(1):19-35

Bjerksund P, Ekern S (1995) Contingent claims evaluation of mean reverting cash flows in shipping. In: Trigeorgis $L$ (ed) Real options in capital investment. Praeger, London, pp 207-221

Boyle PP (1977) Options: a Monte Carlo approach. J Financ Econ 4:323-338

Brennan M, Schwartz E (1977) The valuation of American put options. J Financ 32:449-462

Burel F, Taccani R, Zuliani N (2013) Improving sustainability of maritime transport through utilization of liquefied natural gas (LNG) for propulsion. Energy 57:412-420

Chow JYJ, Regan AC (2011) Real option pricing of network design investments. J Transp Sci 45(1):50-63

Clarksons Research Co. Ltd. n.d. Clarksons Research Database. 2016. https://sin.clarksons.net/.

Cox JC, Ross AS, Rubinstein M (1979) Option pricing: a simplified approach. J Financ Econ 7:229-263

Cullinane K, Bergqvist R (2014) Emission control areas and their impact on maritime transport. Transp. Res. D: Transp Environ, 28, 1-5.

Dikos G (2008) Real option econometrics for aggregate tanker investment decisions. Int J Ocean Syst Manag 1(1):31-33

Dixit A (1989) Entry and exit decisions under uncertainty. J Polit Econ 97(3):620-638

Dixit A (1992) Investment and hysteresis. J Econ Perspect 6(1):107-132

Dixit A, Pindyck R (1994) Investment under uncertainty. Princeton University Press, Princeton

Hopp C, Tsolakis SD (2004) Investment applications in the shipping industry. In: Proceedings of the 8th annual international conference on real Options, 17-19 June, Montréal, Canada

Kavussanons MG, Tsekrekos AE (2011) The option to change the flag of a vessel. In: Cullinane K (ed) International Handbook of Maritime Economics. Edward Elgar, Cheltenham, pp 47-62

Lai VS, Trigeorgis L (1995) The strategic capital budgeting process: a review of theories and practice. In: Trigeorgis L (ed) The capital budgeting process real options in capital investment: models, strategies and applications. Praeger, London, pp 69-96

Li YD (2007) The research on ship investment strategies under uncertainty. In: PhD Thesis. Shanghai Maritime University, Shanghai

Lindstad H, Sandaas I, Strømman AH (2015) Assessment of cost as a function of abatement options in maritime emission control areas. Transp Res D 38(2015):41-48

Longstaff FA, Schwartz ES (2001) Valuing American options by simulation: a simple least-squares approach. Rev Financ Stud 14(1):113-147

Sødal S, Koekebakker S, Adland R (2008) Market switching in shipping -a real option model applied to the valuation of combination carriers. Rev Financ Econ 17(3):183-203

Sødal S, Koekebakker S, Adland R (2009) Value based trading of real assets in shipping under stochastic freight rates. Appl Econ 41(22):2793-2807

Trigeorgis L (1991) Anticipated competitive entry and early preemptive investment in deferrable projects. J Econ Bus 43(2):143-156

Trigeorgis L (1993a) Real options and interaction with financial flexibility. J Financ Manag 22(3):202-224

Trigeorgis $L$ (1993b) The nature of option interactions and the valuation of investments with multiple real options. J Financ Quant Anal 28(1):1-20

Trigeorgis L (1995) Real options in capital investment. In: Models, strategies and applications. Praeger, London

Trigeorgis L (1996) Real options: managerial flexibility and strategy in resource allocation. Massachusetts Institute of Technology, Massachusetts 